\title{
The R21C Mutation in Cardiac Troponin I Imposes Differences in Contractile Force Generation between the Left and Right Ventricles of Knock-In Mice
}

\author{
Jingsheng Liang, Katarzyna Kazmierczak, Ana I. Rojas, \\ Yingcai Wang, and Danuta Szczesna-Cordary \\ Department of Molecular \& Cellular Pharmacology, University of Miami Miller School of Medicine, Miami, FL 33136, USA \\ Correspondence should be addressed to Danuta Szczesna-Cordary; dszczesna@med.miami.edu
}

Received 16 September 2014; Revised 16 December 2014; Accepted 19 December 2014

Academic Editor: Luis Loura

Copyright (c) 2015 Jingsheng Liang et al. This is an open access article distributed under the Creative Commons Attribution License, which permits unrestricted use, distribution, and reproduction in any medium, provided the original work is properly cited.

We investigated the effect of the hypertrophic cardiomyopathy-linked R21C (arginine to cysteine) mutation in human cardiac troponin I (cTnI) on the contractile properties and myofilament protein phosphorylation in papillary muscle preparations from left $(\mathrm{LV})$ and right $(\mathrm{RV})$ ventricles of homozygous $\mathrm{R} 21 \mathrm{C}^{+/+}$knock-in mice. The maximal steady-state force was significantly reduced in skinned papillary muscle strips from the LV compared to RV, with the latter displaying the level of force observed in LV or RV from wild-type (WT) mice. There were no differences in the $\mathrm{Ca}^{2+}$ sensitivity between the $\mathrm{RV}$ and $\mathrm{LV}$ of $\mathrm{R}_{21 \mathrm{C}^{+/+}}$mice; however, the $\mathrm{Ca}^{2+}$ sensitivity of force was higher in RV-R21C ${ }^{++}$compared with RV-WT and lower in LV- $\mathrm{R} 21 \mathrm{C}^{+/+}$compared with LV-WT. We also

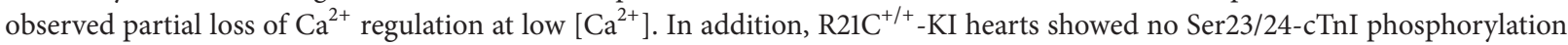
compared to LV or RV of WT mice. However, phosphorylation of the myosin regulatory light chain (RLC) was significantly higher in the $\mathrm{RV}$ versus $\mathrm{LV}$ of $\mathrm{R}_{21 \mathrm{C}^{+/+}}$mice and versus $\mathrm{LV}$ and $\mathrm{RV}$ of WT mice. The difference in RLC phosphorylation between the ventricles of $\mathrm{R}_{2} 1 \mathrm{C}^{+/+}$mice likely contributes to observed differences in contractile force and the lower tension monitored in the $\mathrm{LV}$ of HCM mice.

\section{Introduction}

The pump function of the heart is achieved by a sequence of alternating contraction and relaxation of the heart muscle. Although both the left (LV) and right (RV) ventricles contract simultaneously, there are functional and structural differences between them. Since the LV is responsible for pumping blood throughout most vessels in the body, it generates more pressure and therefore it is thicker than the RV. A normal LV has a near conical geometry with its long-axis directed from apex to base and irregular endocardial surface due to the presence of papillary muscles and trabeculae [1]. Several studies using experimental mechanics and computational modeling have proved that the helical geometry of the muscle fibers of the LV changes gradually from right-handed in the subendocardium to left-handed in the subepicardium, which produces a distinctive counter directional movement of the fiber layers in a beating heart [2-5]. The RV is less muscular because it operates at a lower pressure compared to the LV and pumps blood through the shorter distance to the lungs. In addition, the RV does very little work against gravity. The stroke work for RV is approximately $25 \%$ of that for LV because of low resistance of the pulmonary vasculature. Morphologically, the RV is distinguished from the LV by having coarser trabeculae and a lack of fibrous continuity between its inflow and outflow valves $[6,7]$.

Despite efforts by many, the contractile differences between the RV and LV in the healthy and/or diseased heart are poorly understood. For example, no differences were observed in the stress development, twitch duration, work performance, or shortening power between the RV and LV in dogs $[8,9]$. On the other hand, small differences were observed in the contractile performance and growth of the LV and RV myocytes in dilated cardiomyopathy [10] and in 
myofilament function in congestive heart failure [11]. Likewise, molecular analysis of the myocardial tissue of the explanted heart of familial hypertrophic cardiomyopathy (HCM) patients showed similar mRNA and $\beta$-MHC protein expression levels in both ventricles but the hypertrophic phenotype was only observed in the LV [12].

This report aimed to examine the functional differences between the LV and RV at the level of papillary muscle fibers from the knock-in (KI) mice expressing the HCM-linked R21C (arginine to cysteine) mutation in cardiac troponin I (cTnI) shown to cause a malignant HCM phenotype [13]. The animal model of R21C-HCM was produced and characterized previously $[14,15]$. Here we show a significant functional difference in contractile force generation between the LV and $\mathrm{RV}$ in the disease model expressing the R21C cTnI mutation which is not present in wild-type (WT) control mice. The presence of the effect of the mutation only in the LV is the testimony to the power of the mutation exerting detrimental effects on the function of the LV.

\section{Materials and Methods}

All animal studies were conducted in accordance with institutional guidelines. The University of Miami has an Animal Welfare Assurance (A-3224-01, effective November $23,2011)$ on file with the Office of Laboratory Animal Welfare (OLAW), National Institutes of Health. The mouse model of R21C-HCM was generated and characterized earlier [14]. Seven nine-month-old homozygote $\mathrm{R}^{2} \mathrm{C}^{+/+} \mathrm{KI}$ mice were used in the experiments and the results were compared to those of age and gender matched WT controls.

2.1. Histopathological Characterization. After euthanasia, the hearts from $\sim 7$-month-old WT and $\mathrm{R}^{2} 1 \mathrm{C}^{+/+} \mathrm{KI}$ mice were excised and immersed in $10 \%$ buffered formalin. Slides of whole mouse hearts were prepared at the Histology Laboratory (University of Miami Miller School of Medicine, Miami, FL). Paraffin-embedded longitudinal sections of whole mouse hearts stained with hematoxylin and eosin (H\&E) and Masson's trichrome were examined for overall morphology and fibrosis using a Dialux 20 microscope, 40/0.65 NA (numerical aperture) Leitz Wetzlar objective, and an AxioCam HRc (Zeiss) as described previously [16, 17].

\subsection{Preparation of Glycerinated Left and Right Ventricular} Muscle Strips. The papillary muscles of the left and right ventricles from flash frozen hearts of $\mathrm{R}_{21 \mathrm{C}^{+/+}} \mathrm{KI}$ mice were isolated, dissected into muscle bundles in the buffer containing pCa 8 solution $\left(10^{-8} \mathrm{M}\left[\mathrm{Ca}^{2+}\right], 1 \mathrm{mM}\right.$ free $\left[\mathrm{Mg}^{2+}\right]$ (total $\operatorname{MgPr}$ (propionate) $=3.88 \mathrm{mM}$ ), $7 \mathrm{mM}$ EGTA, $2.5 \mathrm{mM}[\mathrm{Mg}-$ $\mathrm{ATP}^{2-}$ ], $20 \mathrm{mM}$ MOPS, pH 7.0, $15 \mathrm{mM}$ creatine phosphate, and 15 units $/ \mathrm{mL}$ of phosphocreatine kinase, ionic strength $=150 \mathrm{mM}$ adjusted with $\mathrm{KPr}$ ), $15 \%$ glycerol, and $30 \mathrm{mM}$ $\mathrm{BDM}$. Solutions of increasing $\mathrm{Ca}^{2+}$ concentrations from $\mathrm{pCa}$ $8\left(\left[\mathrm{Ca}^{2+}\right]=10^{-8} \mathrm{M}\right)$ to $\mathrm{pCa} 4\left(\left[\mathrm{Ca}^{2+}\right]=10^{-4} \mathrm{M}\right)$ were prepared based on the "pCa-Calculator" program developed by Dweck et al. [18]. Muscle bundles were skinned in $50 \%$ pCa 8 solution and $50 \%$ glycerol containing $1 \%$ Triton X-100 for $24 \mathrm{hr}$ at $4^{\circ} \mathrm{C}$.
Muscle bundles were then transferred to the same solution without Triton X-100 and stored at $-20^{\circ} \mathrm{C}$ for experiments within $\sim 5$ days [19].

2.3. Steady-State Force Development. Small muscle strips of approximately $1.4 \mathrm{~mm}$ in length and $100 \mu \mathrm{m}$ in diameter were isolated from a batch of glycerinated skinned mouse papillary muscle bundles and attached by tweezer clips to a force transducer. The strips were placed in a $1 \mathrm{~mL}$ cuvette and freshly skinned in 1\% Triton X-100 dissolved in pCa 8 buffer for $30 \mathrm{~min}$. The sarcomere length was adjusted to $\sim 2.1 \mu \mathrm{m}$ and the maximal steady-state force was measured in $\mathrm{pCa} 4$ solution (composition is the same as pCa 8 buffer except the $\left[\mathrm{Ca}^{2+}\right]=$ $10^{-4} \mathrm{M}$ ). Maximal tension readings (in pCa 4) were taken before and after the force-pCa curve, averaged, and expressed in $\mathrm{kN} / \mathrm{m}^{2}$. The cross-sectional area of the muscle strip was assumed to be circular [16].

2.4. The $\mathrm{Ca}^{2+}$ Dependence of Force Development. After determination of initial steady-state force, muscle strips were relaxed in pCa 8 buffer and exposed to solutions of increasing $\mathrm{Ca}^{2+}$ concentrations from pCa 8 to $\mathrm{pCa} 4$ [18]. The level of force was measured in each " $\mathrm{pCa}$ " solution. Data were analyzed using the Hill equation [20], where " $\left[\mathrm{Ca}^{2+}\right]_{50}$ or $\mathrm{pCa}_{50}$ " is the free $\mathrm{Ca}^{2+}$ concentration which produces $50 \%$ of the maximal force and $n_{\mathrm{H}}$ is the Hill coefficient. The $\mathrm{pCa}_{50}$ represents the measure of $\mathrm{Ca}^{2+}$ sensitivity of force and the $n_{\mathrm{H}}$ is the measure of myofilament cooperativity.

2.5. Passive Force Measurements. The measurement of passive force (in pCa 8 solution) in response to muscle stretch was performed as described in [16]. Briefly, after skinning the strips were washed in the relaxing solution and their length was adjusted to remove the slack. This procedure resulted in sarcomere length (SL) of $\sim 2.1 \mu \mathrm{m}$ as judged by the first order optical diffraction using a He-Ne laser [21, 22]. This point was set as zero for both the passive force and starting length of the muscle strip. Then, the strips were stretched by $10 \%$ of its length $\times 4$ consecutive times, and the passive force per crosssection of muscle (in $\mathrm{kN} / \mathrm{m}^{2}$ ) was determined.

2.6. Analysis of Protein Phosphorylation. Flash frozen LV and RV from all groups were homogenized in CMF buffer consisting of $5 \mathrm{mM} \mathrm{NaH} \mathrm{PO}_{4}, 5 \mathrm{mM} \mathrm{Na}_{2} \mathrm{HPO}_{4}$ ( $\mathrm{pH} 7.0$ ), $0.1 \mathrm{mM} \mathrm{NaCl}, 5 \mathrm{mM} \mathrm{MgCl}_{2}, 0.5 \mathrm{mM}$ EGTA, $5 \mathrm{mM}$ ATP, $5 \mathrm{nM}$ microcystin, $0.1 \%$ Triton X-100, $20 \mathrm{mMNaF}$ (phosphatase inhibitor), $5 \mathrm{mM}$ DTT, and $1 \mu \mathrm{L} / \mathrm{mL}$ protease inhibitor cocktail. The samples were homogenized for $2 \mathrm{~min}$ in a MixerMill MM301 at $30 \mathrm{~Hz}$, chilled on ice, and homogenized again for $2 \mathrm{~min}$. Homogenates were then centrifuged for $4 \mathrm{~min}$ at $1800 \mathrm{~g}$ and the supernatants were discarded. The pellets were resuspended in the CMF buffer and the myofibrils were subsequently dissolved in SDS-PAGE sample buffer and loaded on $15 \%$ SDS-PAGE. The phosphorylated form of myosin regulatory light chain (RLC) was detected with phosphospecific RLC antibodies (produced earlier [23]), which recognize the phosphorylated form of the RLC followed by a secondary goat anti-rabbit antibody conjugated with the fluorescent 


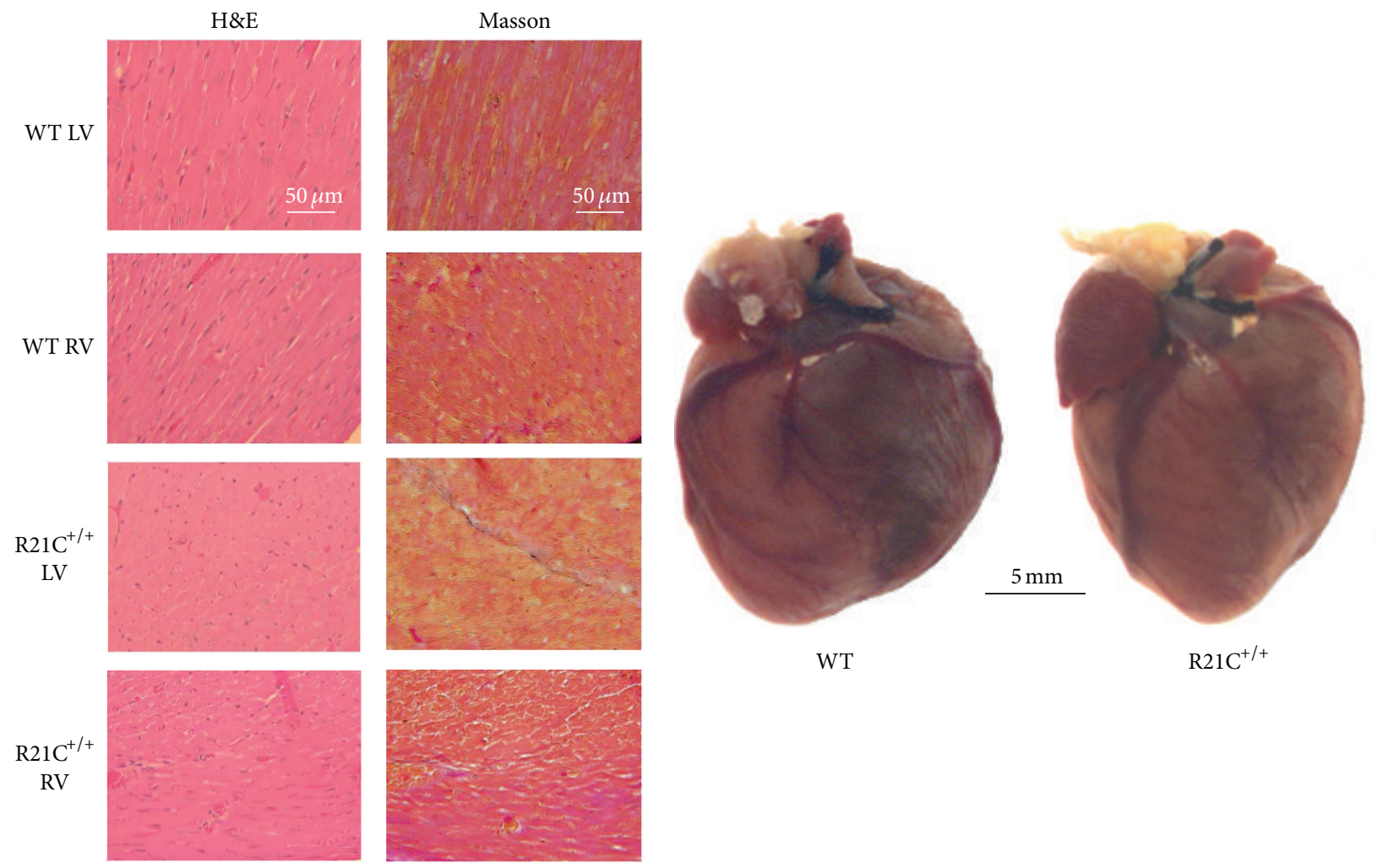

FIGURE 1: Representative hearts and H\&E and Masson's trichrome-stained LV and RV sections from R21C ${ }^{/+}$and WT mice. LV and RV sections from the hearts of $\sim 7$-month-old male R21C ${ }^{+/+}$and WT mice were imaged. Note: no mutation-induced abnormalities in H\&E stained sections from the hearts of $\mathrm{R}_{21 \mathrm{C}^{+/+}}$compared with WT mice. Very mild histopathological changes could infrequently be observed in Masson's trichrome-stained LV sections from $\mathrm{R}_{2} 1 \mathrm{C}^{+/+}$mice.

dye, IR red 800. The total RLC protein was detected with polyclonal RLC CT-1 antibodies produced in this laboratory [19] (raised against 15 residues from the C-terminus of human cardiac RLC) and served as a loading control. Mouse cardiac myofibrils from LV and RV were also used to determine sarcomeric protein phosphorylation by ProQ/Coomassie [17]. After separation of the samples on 15\% SDS-PAGE ProQ Diamond phosphoprotein gel stain reagent (Invitrogen) was used (as described in the manufacturer's manual) to assess phosphorylation of troponin (TnT, TnI) and myosin RLC. The total protein was further detected in the same gel using the Coomassie brilliant blue staining. Myofilament protein phosphorylation ratio (ProQ) was calculated relative to the corresponding Coomassie brilliant blue staining (ProQ/Coomassie) using Image J software.

2.7. Statistical Analysis. All values are shown as means \pm SEM (standard error of the mean). Statistically significant differences between two groups were determined using an unpaired Student's $t$-test, with significance defined as $P<$ 0.05. Comparisons between multiple groups were performed using one-way ANOVA (Sigma Plot 11; Systat Software, San Jose, CA). Passive tension measurements were analyzed using one-way repeated measures ANOVA (IBM SPSS statistics version 21).

\section{Results}

3.1. Histology. Representative H\&E and Masson's trichromestained LV and RV sections from the hearts of $\sim 7$-monthold male $\mathrm{R}_{21 \mathrm{C}^{+/+}}$and WT mice and images of the whole hearts are presented in Figure 1. The heart tissue morphology pictured in $\mathrm{H} \& \mathrm{E}$ stained slides showed no mutation-induced abnormalities in LV or $\mathrm{RV}$ of $\mathrm{R}^{2} 1 \mathrm{C}^{+/+}$mice. Very mild histopathological changes could occasionally be seen in Masson's trichrome-stained LV sections from $\mathrm{R}_{21 \mathrm{C}^{+/+}}$mice compared to WT controls, but no obvious signs of fibrosis or myofilament disarray were observed. These results are in accord with previous findings on $\mathrm{R}^{2} 1 \mathrm{C}^{+/+}$mice showing no abnormalities in the hearts of 3-6-month-old mutant versus WT mice [14]. Substantial morphological changes with severe fibrotic lesions were observed in animals as old as 18 months [14].

3.2. The R21C Mutation in cTnI Imposes Differences in Maximal Steady-State Force in the $L V$ but Not in $R V$. Measurements of steady-state force were performed in skinned papillary muscle strips from the $\mathrm{LV}$ and $\mathrm{RV}$ of $\mathrm{R}_{21 \mathrm{C}^{+/+}} \mathrm{KI}$ homozygous mice and the results were compared to WT mice (Figures 2(a) and 2(b)). Three to four hearts per group were used with each heart yielding 5-8 muscle strips from LV 
TABLE 1: The effect of R21C mutation in TnI on steady-state force measurements in $\mathrm{KI} \mathrm{R} 21 \mathrm{C}^{+/+}$mice.

\begin{tabular}{lcccc}
\hline Parameter & $\begin{array}{c}\text { LV-WT mice } \\
\text { Three mice; 22 fibers }\end{array}$ & $\begin{array}{c}\text { RV-WT mice } \\
\text { Three mice; 16 fibers }\end{array}$ & $\begin{array}{c}\text { LV-R21C } \\
\text { Four mice; 30 fibers }\end{array}$ & $\begin{array}{c}\text { RV-R21C }^{+/+} \text {mice } \\
\text { Four mice; 30 fibers }\end{array}$ \\
\hline Maximal tension/cross-section $\left(\mathrm{kN} / \mathrm{m}^{2}\right)$ & $41.8 \pm 0.8$ & $41.7 \pm 0.6$ & $36.9 \pm 1.2$ & $43.5 \pm 1.0$ \\
$\mathrm{pCa}_{50}$ (calcium sensitivity) & $5.76 \pm 0.02$ & $5.67 \pm 0.03$ & $5.71 \pm 0.01$ & $5.73 \pm 0.01$ \\
$n_{\mathrm{H}}$ (Hill coefficient) & $2.16 \pm 0.14$ & $1.90 \pm 0.10$ & $2.19 \pm 0.10$ & $2.20 \pm 0.09$ \\
\hline
\end{tabular}

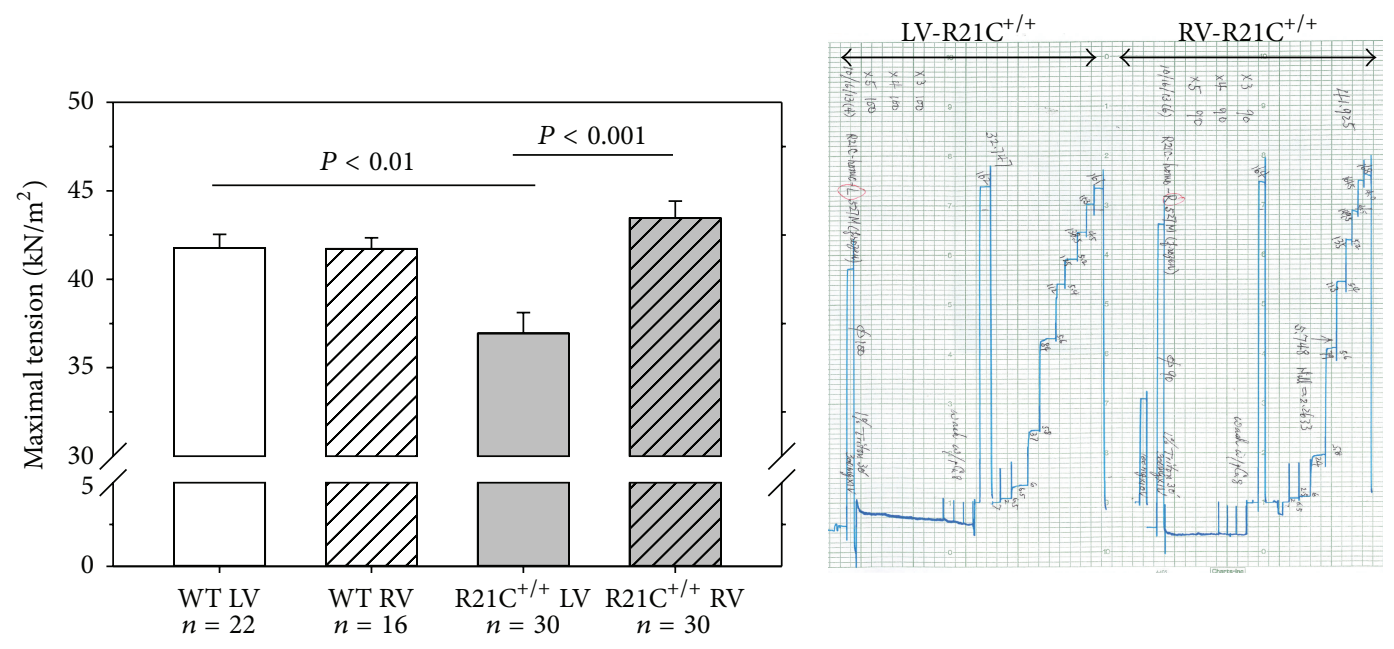

(a)

(b)

Figure 2: The effect of the HCM-R21C mutation in cTnI on steady-state force development in LV versus RV papillary muscle strips in genetically altered mice. (a) Maximal tension per cross-section of muscle strip. Note that the R21C mutation in cTnI imposes differences in maximal steady-state force in the LV but not in RV. Sixteen to thirty independent measurements on skinned cardiac muscle strips from the left and right ventricles of three WT hearts and four homozygous $\mathrm{R}_{2} 1 \mathrm{C}^{+/+}$knock-in hearts have been performed. $\sim 8$-month-old mice were used yielding, respectively, $n=22$ and $n=16$ muscle strips from the LV and RV of WT mice and $n=30$ muscle strips from LV and RV of $\mathrm{R}_{21 \mathrm{C}^{+/+}}$mice. Error bars are SEM. (b) Representative force traces in the LV and RV papillary muscle fibers of R21C $\mathrm{mice}^{+/+}$

and RV that were used in mechanical experiments (Table 1). A significantly lower maximal isometric force was observed in $\mathrm{LV}$ of $\mathrm{R} 21 \mathrm{C}^{+/+}$mice $\left(36.9 \pm 1.2 \mathrm{kN} / \mathrm{m}^{2}, n=30\right.$ strips $)$ compared to LV-WT $\left(41.8 \pm 0.8 \mathrm{kN} / \mathrm{m}^{2}, n=22\right)$ strips (Figure 2 and Table 1). The differences in the level of force in $\mathrm{LV}-\mathrm{R}_{21 \mathrm{C}^{+/+}}$versus all other muscles including $\mathrm{RV}-\mathrm{R}_{2} 1 \mathrm{C}^{+/+}$ $\left(43.5 \pm 1.0 \mathrm{kN} / \mathrm{m}^{2}, n=30\right)$ were also statistically significant (Figure $2, P<0.001$ ). There were no differences between WT-LV and WT-RV $\left(41.7 \pm 0.6 \mathrm{kN} / \mathrm{m}^{2}, n=16\right)$ or RV$\mathrm{R}_{21 C^{+/+}}$(Figure 2(a) and Table 1). Therefore, the mutation exerted its effect only on the LV and not RV while there were no differences between ventricles of WT mice.

\subsection{Force-pCa Relationship Is Rightward Shifted in the LV but} Leftward Shifted in $R V$ in $R 21 C^{+/+}$Compared to WT Mice. As shown in Figures 3(a) and 3(b), there was a significant difference in the $\mathrm{Ca}^{2+}$ sensitivity of force between LV-WT $\left(\mathrm{pCa}_{50}=5.76 \pm 0.02, n=22\right)$ and RV-WT $(5.67 \pm 0.03$, $n=16)$ muscles and the $\mathrm{Ca}^{2+}$ sensitivity of force was rightward shifted in the RV of WT mice compared to LVWT (Figure 3(b), Table 1). The Hill coefficient (parameter of cooperativity) was also slightly lower in RV-WT $\left(n_{\mathrm{H}}=\right.$ $1.90 \pm 0.10)$ compared to LV-WT $\left(n_{\mathrm{H}}=2.16 \pm 0.14\right)$, but the difference was not statistically significant (Table 1). Considering the $\mathrm{HCM} \mathrm{R} 21 \mathrm{C}^{+/+}$heart, the mutation exerted no statistically significant changes in the $\mathrm{Ca}^{2+}$-sensitivity of contraction between the LV and RV (Figure 3). The HCM phenotype of the R21C mutation was manifested by a small but significant change in the $\mathrm{Ca}^{2+}$ sensitivity in the LV$\mathrm{R}_{21 \mathrm{C}^{+/+}}\left(5.71 \pm 0.01, n_{\mathrm{H}}=2.19 \pm 0.10, n=30\right)$ compared to the LV-WT. However, as observed for other HCM mutations, the force-pCa relation was leftward shifted in the RV of $\mathrm{R}_{21 \mathrm{C}^{+/+}}$mice $\left(5.73 \pm 0.01, n_{\mathrm{H}}=2.20 \pm 0.09, n=30\right)$ compared to RV-WT (Figure 3, $P<0.05$ ).

\subsection{The R21C Mutation in cTnI Imposes Differences in Passive} Force in the LV but Not in $R V$. The measurement of passive tension in response to muscle stretch was performed in pCa 8 relaxing solution as described in [16]. The data are expressed as fold change over the active force measured in $\mathrm{kN} / \mathrm{m}^{2}$ in $\mathrm{pCa} 4$ solution before the first $10 \%$ stretch of the fiber length (Figure 4). Data are average of 9-10 experiments performed on skinned papillary muscle strips from flash frozen hearts of 9-month-old male mice. The effect of mutation on passive tension followed the trend observed in active tension development presented in Figure 2. Passive 


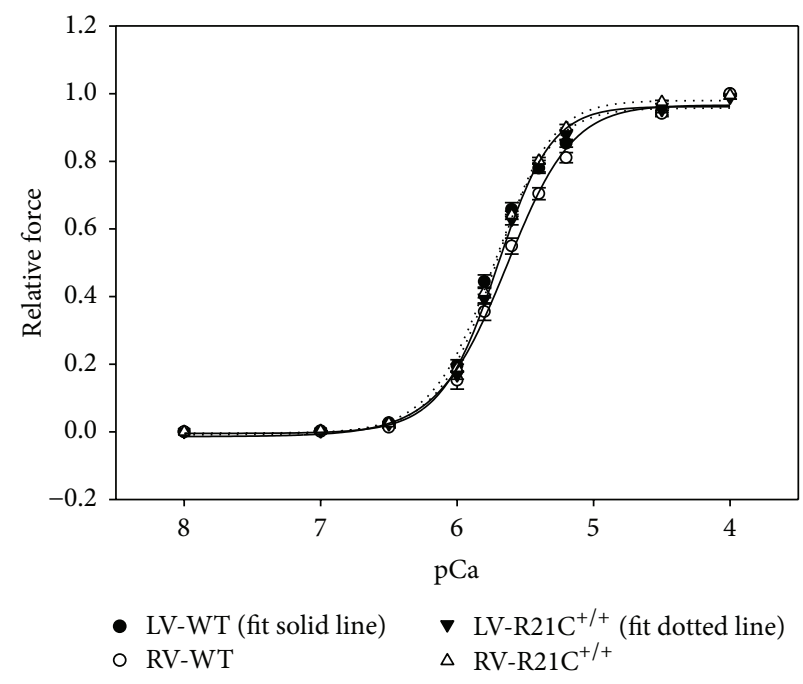

(a)

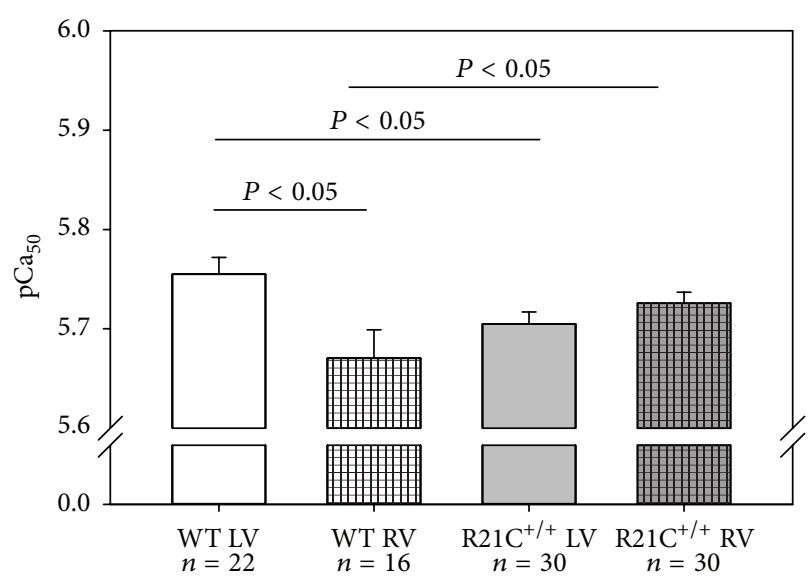

(b)

FIgure 3: Force-pCa dependence (a) and $\mathrm{Ca}^{2+}$-sensitivity (b) in LV and RV of R21C ${ }^{+/+}$mice compared with LV and RV of WT mice. Note that the $\mathrm{Ca}^{2+}$ sensitivity of force was lower in RV-WT compared to LV-WT $(P<0.05)$. The $\mathrm{Ca}^{2+}$ sensitivity of force was also lower in the $\mathrm{LV}$ of $\mathrm{R}_{21 \mathrm{C}^{+/+}}$mice versus LV-WT. The $\mathrm{pCa}_{50}$ was larger in the RV-R21C $\mathrm{C}^{+/+}$compared to RV of WT mice $(P<0.05)$. No differences in the force-pCa dependence were observed between the $\mathrm{LV}$ versus $\mathrm{RV}$ of $\mathrm{R}_{21 \mathrm{C}^{+/+}}$mice. Number of mice and muscle strips are as in Figure 2. Error bars are SEM.

tension was significantly higher in $\mathrm{LV}-\mathrm{R} 21 \mathrm{C}^{+/+}$compared to LV-WT for all points of stretch (Figure $4, P=0.015$ ). No significant changes in the resistance to stretch were noted for other groups of strips. The level of passive tension for $10 \%$ stretch (in $\left.\mathrm{kN} / \mathrm{m}^{2}\right)$ was $2.2 \pm 0.4(\mathrm{LV}-\mathrm{WT}) ; 2.9 \pm 0.5(\mathrm{RV}-$ $\mathrm{WT}) ; 7.1 \pm 2.2\left(\mathrm{LV}-\mathrm{R} 21 \mathrm{C}^{+/+}\right)$; and $4.4 \pm 1.0\left(\mathrm{RV}-\mathrm{R} 21 \mathrm{C}^{+/+}\right)$. Interestingly, the difference between $\mathrm{LV}-\mathrm{R} 21 \mathrm{C}^{+/+}$and $\mathrm{LV}-\mathrm{WT}$ was statistically significant $(P=0.027)$ indicating partial loss of $\mathrm{Ca}^{2+}$ regulation at low $\left[\mathrm{Ca}^{2+}\right]$ in the mutant $\mathrm{LV}$. Therefore, once again, it is important to note that the effect of a disease causing mutation was manifested in the papillary muscle strips from the LV (and not RV), the ventricle which is predominantly affected by HCM disease.

\subsection{The R21C Mutation Prevents cTnI Phosphorylation in Both} Ventricles but Imposes Differences in RLC Phosphorylation between the $L V$ and $R V$. As shown in Figures 5(a) and 5(c), there were no differences in cTnI phosphorylation between the LV and RV of WT mice. Consistent to what was observed earlier in this $\mathrm{R}^{2} 1 \mathrm{C}^{+/+}-\mathrm{KI}$ mouse model of HCM $[14,15]$, the mutation prevented $\beta$-adrenergic-activated protein kinase A(PKA-) mediated phosphorylation of cTnI at Ser 23 and 24. Data were derived from four independent ProQ/Coomassie gels assessed in 2-3 preparations from $\mathrm{LV}$ and $\mathrm{RV}$ of $\mathrm{R} 21 \mathrm{C}^{+/+}$ and WT mice. No changes in phosphorylation of troponin $\mathrm{T}$ ( $\mathrm{TnT}$ ) or myosin binding protein C (MyBP-C) were observed between the groups of fibers (Figure 5(a)). However, the mutation imposed a significant alteration in the myosin RLC phosphorylation between the $\mathrm{LV}$ and $\mathrm{RV}$ of $\mathrm{R}_{2} 1 \mathrm{C}^{+/+}$mice (Figures 5(b) and 5(d)). Data for RLC phosphorylation were derived from six independent SDS-PAGE (Western blots and ProQ/Coomassie gels) analyses of two to three LV and
RV preparations per group. Interestingly, phosphorylation of myosin RLC was significantly higher in the RV versus $\mathrm{LV}$ of $\mathrm{R}^{2} 1 \mathrm{C}^{+/+}$mice (Figures 5(b) and $5(\mathrm{~d}), P=0.007$ ) and also significantly higher than in LV-WT (Figures $5(\mathrm{~b})$ and 5(d), $P=0.027)$. Elevated RLC phosphorylation in the $\mathrm{RV}$ of $\mathrm{R}_{21 \mathrm{C}^{+/+}}$mice may play rescuing role in preventing the right ventricle from abnormalities in force development that are observed in the $\mathrm{LV}$ of $\mathrm{R}_{2} 1 \mathrm{C}^{+/+}$mice. No statistically significant differences in myosin RLC phosphorylation were observed between the LV and RV of WT mice (Figure 5(d), $P>0.05)$.

\section{Discussion}

In this study, we aimed to examine the effect of the HCMlinked R21C in cTnI on the function and protein phosphorylation and pinpoint potential differences between the LV and $\mathrm{RV}$ using papillary muscle fibers from the KI homozygous mice compared to WT. The R21C mutation was identified in a cardiomyopathy patient, who presented with atrial fibrillation shortly after the sudden death of her child at the age of 18 years [13]. Three surviving mutation carriers from the family had asymmetrical septal hypertrophy, left atrial enlargement, and normal cardiac dimensions. The mutation was also identified in another HCM family with 4 mutation carriers having subaortic asymmetrical hypertrophy and one mutation carrier with normal cardiac dimensions, who was resuscitated from sudden death [13]. The animal model of R21C-HCM used in this study was produced and characterized previously $[14,15]$. In agreement with those reports, we show that the mutation renders no obvious histopathological changes in 7-month-old mice compared to age and gender matched 


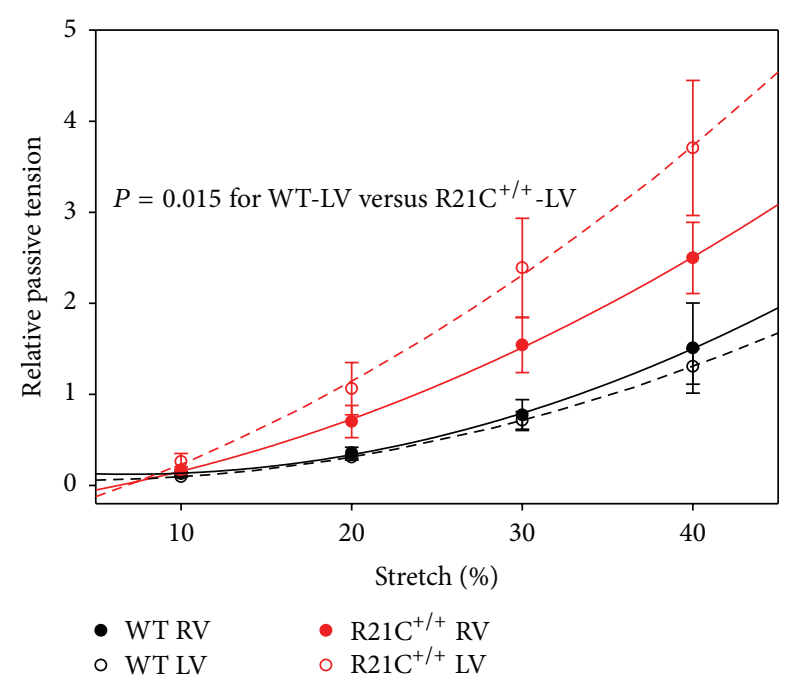

FIGURE 4: Passive tension per cross-section of muscle strip in LV and $\mathrm{RV}$ of $\mathrm{R}_{2} 1 \mathrm{C}^{+/+}$mice compared with $\mathrm{LV}$ and $\mathrm{RV}$ of WT mice. After skinning the strips were washed in the relaxing solution and their length was adjusted to remove the slack to sarcomere length (SL) = $\sim 2.1 \mu \mathrm{m}$. This point was set as zero for both the passive force and starting length of the muscle strip. Then, the strips were stretched by $10 \%$ of its length $\times 4$ consecutive times, and the passive force per cross-section of muscle (in $\mathrm{kN} / \mathrm{m}^{2}$ ) was determined. Note that the R21C mutation exerted its effect on passive tension in the LV compared to $\operatorname{LV}-\mathrm{WT}$ ( $P=0.015$ as established by repeated measures ANOVA). The values of passive tension (in $\mathrm{kN} / \mathrm{m}^{2}$ ) for $10 \%, 20 \%$, $30 \%$, and $40 \%$ stretch were $2.2 \pm 0.4 ; 7.9 \pm 0.7 ; 19.6 \pm 1.8$; and $38.7 \pm 3.5$ for LV-WT and $6.4 \pm 2.1 ; 26.6 \pm 7.5$; $59.7 \pm 15.5$; and $92.1 \pm 21.7$ for $\mathrm{LV}-\mathrm{R} 21 \mathrm{C}^{+/+}$. No statistical differences in the resistance to stretch were observed between the LV versus RV of WT mice. Interestingly, the passive tension for $10 \%$ stretch (in $\mathrm{kN} / \mathrm{m}^{2}$ ) was $2.2 \pm 0.4(\mathrm{LV}-\mathrm{WT}) ; 2.9 \pm 0.5(\mathrm{RV}-\mathrm{WT}) ; 7.1 \pm 2.2\left(\mathrm{LV}-\mathrm{R} 21 \mathrm{C}^{+/+}\right)$; and

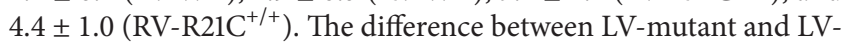
WT was statistically significant $(P=0.027)$ indicating mutationinduced partial loss of $\mathrm{Ca}^{2+}$ regulation at low $\mathrm{Ca}^{2+}$. Data are average of $n=9-10$ experiments performed on skinned muscle strips from 9-month-old male mice. Error bars are SEM.

WT (Figure 1). Likewise, as shown earlier, we observed no cTnI phosphorylation in $\mathrm{R}^{2} 1 \mathrm{C}^{+/+}$mice (Figure 5). However, we show here that the R21C mutation in cTnI imposes significant functional differences in contractile force generation in genetically altered $\mathrm{KI}-\mathrm{R} 21 \mathrm{C}^{+/+}$compared to WT mice. In contrast to Wang et al., 2012 [14], a significantly lower maximal pCa 4 force was observed in $\mathrm{R}_{21 C^{+/+}}$compared with WT mice (Figure 2). Importantly, this difference in maximal tension per cross-section of muscle occurred only in the $\mathrm{LV}$ and not in the RV of $\mathrm{R}^{2} 1 \mathrm{C}^{+/+}$mice (Figure 2). This result highlights the importance of testing cardiac muscle preparations from both ventricles when studying the effect of HCM causing mutations in mice. Interestingly, passive tension in $\mathrm{R}_{21 \mathrm{C}^{+/+}}$mice followed the active force measurements and the only difference between $\mathrm{R} 1 \mathrm{C}^{+/+}$and WT fibers was observed in the LV. A significantly larger value for passive tension was observed in $\mathrm{LV}-\mathrm{R} 21 \mathrm{C}^{+/+}$compared to LV-WT (Figure 4, $P=0.015$ ). No statistically significant changes in the resistance to stretch were noted for other groups of muscle strips. In addition, the value of passive tension for $10 \%$ stretch was 3.2 -fold larger in $\mathrm{LV}-\mathrm{R} 21 \mathrm{C}^{+/+}$ than in LV-WT $(P=0.027)$. Elevated passive tension measured in the $\mathrm{LV}$ of $\mathrm{R}_{21 \mathrm{C}^{+/+}}$versus WT mice indicated partial loss of $\mathrm{Ca}^{2+}$ regulation at low $\left[\mathrm{Ca}^{2+}\right]$. Therefore, once again, it is important to note that the effect of a disease causing mutation was manifested in the papillary muscle strips from the LV (and not RV), the ventricle which is predominantly affected due to HCM disease.

There are various functional differences between the LV and RV of WT mice that could arise from differences in external loads of both ventricles, differently occurring posttranslational modifications, and so forth, and be manifested by changes in the myofilament $\mathrm{Ca}^{2+}$ sensitivity between $\mathrm{LV}$ and RV. In agreement with the study by Perreault et al. [24] and Belin et al. [11], we observed a rightward shift in the force-pCa curve in the RV versus LV of WT mice (Figure 3). There were no differences in the $\mathrm{Ca}^{2+}$ sensitivity between the $\mathrm{RV}$ and $\mathrm{LV}$ of $\mathrm{R} 21 \mathrm{C}^{+/+}-\mathrm{KI}$ mice. In $\mathrm{R}^{2} \mathrm{C}^{+/+}$mice, the R21C mutation disrupts the PKA consensus sequence preventing PKA-dependent phosphorylation of Ser 23/24 of TnI that occurs in response to $\beta$-adrenergic stimulation in WT mice resulting in faster relaxation and desensitization of myofilaments to calcium [25-28]. As seen for the majority of HCM causing mutations, especially for the regulatory troponin proteins $[29,30]$, the R21C mutation left shifted the $\mathrm{Ca}^{2+}$ sensitivity of force but only in the RV compared to RVWT. The HCM phenotype in the $\mathrm{LV}$ of $\mathrm{R}^{2} \mathrm{CC}^{+/+}-\mathrm{KI}$ mice was manifested by a rightward shift in the $\mathrm{Ca}^{2+}$ sensitivity of force compared to LV of WT mice. A mutation-elicited response in the $\mathrm{LV}$ of $\mathrm{R}_{21 \mathrm{C}^{+/+}}$mice was similar to that observed on $\beta$-adrenergic stimulation causing desensitization of myofilaments to calcium. However, the latter did not occur due to the PKA-dependent phosphorylation of TnI, which was absent in $\mathrm{R}_{21 \mathrm{C}^{+/+}}$mice. Regarding the phenotypes between the LV and $\mathrm{RV}$, the mutant showed a significantly lower $\mathrm{Ca}^{2+}$ sensitivity $\left(\mathrm{pCa}_{50}\right)$ than WT in the LV, while it resulted in larger $\mathrm{pCa}_{50}$ than WT in the RV (Figure 3(b)). In conclusion, the HCM phenotype in $\mathrm{R}_{21 \mathrm{C}^{+/+}}$mice was manifested by the lack of differences in the $\mathrm{Ca}^{2+}$ sensitivity of force between the LV and $\mathrm{RV}$ that were clearly observed in the ventricles of WT mice.

To elucidate the reason for contractile differences (in force and calcium sensitivity) observed in $\mathrm{R}_{21 \mathrm{C}^{+/+}}$versus WT mice, we have examined sarcomeric protein phosphorylation in the LV and RV of mice (Figure 5). The phosphorylation level of cTnI was not different between the LV and RV of WT mice, while no phosphorylation of cTnI was seen in $\mathrm{LV}-\mathrm{R} 21 \mathrm{C}^{+/+}$and $\mathrm{RV}-\mathrm{R} 21 \mathrm{C}^{+/+}$(Figures 5(a) and 5(c)). As observed in this study, the R21C mutation was shown before to prevent the PKA-dependent phosphorylation of Ser 23 and Ser 24 of cTnI $[14,29]$. In addition, no mutation exerted changes were observed in phosphorylation of TnT or MyBP-C (Figure 5(a)). However, a significant R21Cmediated enhancement of myosin RLC phosphorylation was observed in the RV compared with $\mathrm{LV}$ of $\mathrm{R} 21 \mathrm{C}^{+/+}-\mathrm{KI}$ mice 


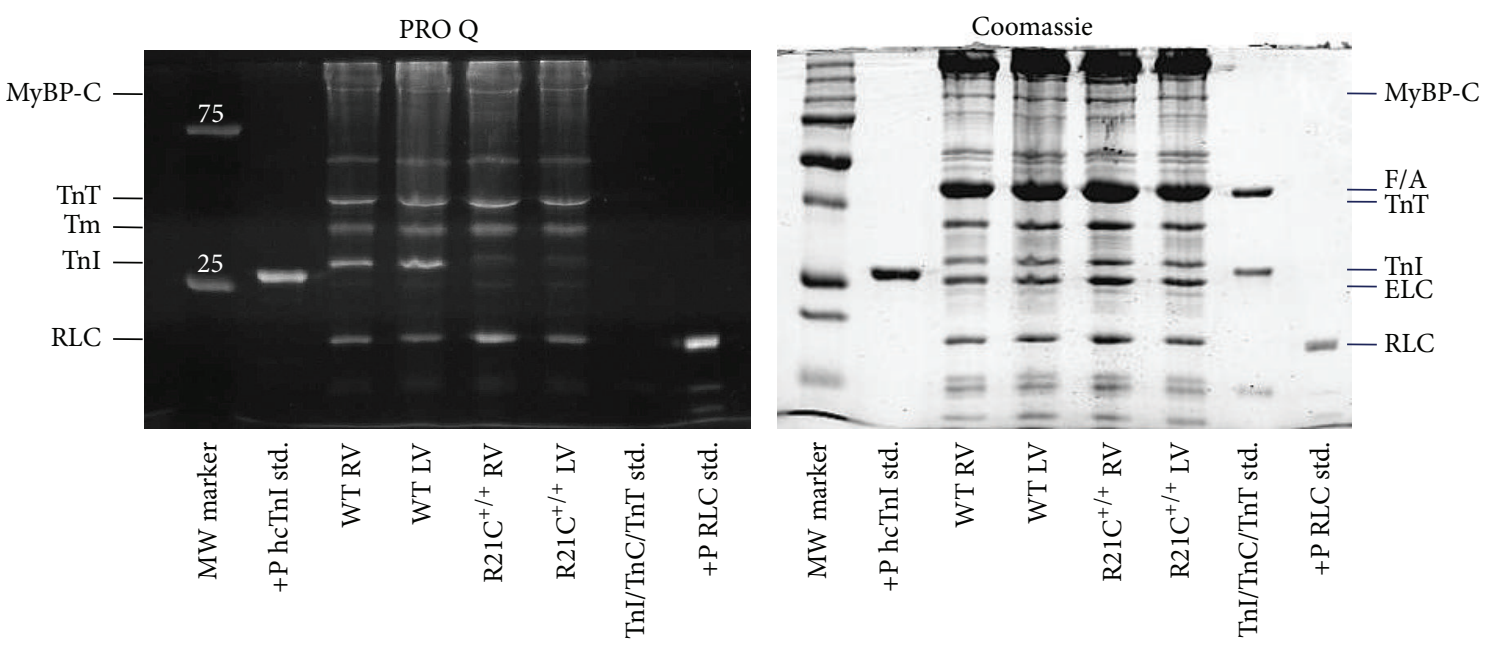

(a)

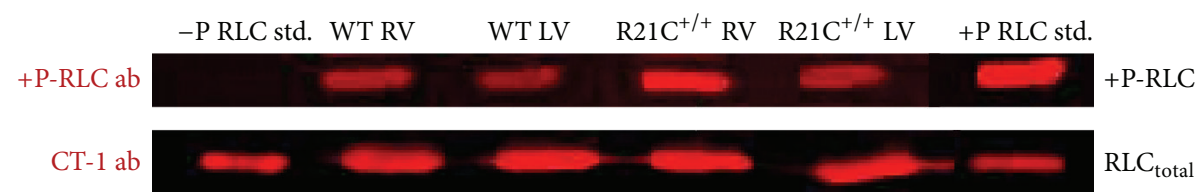

(b)

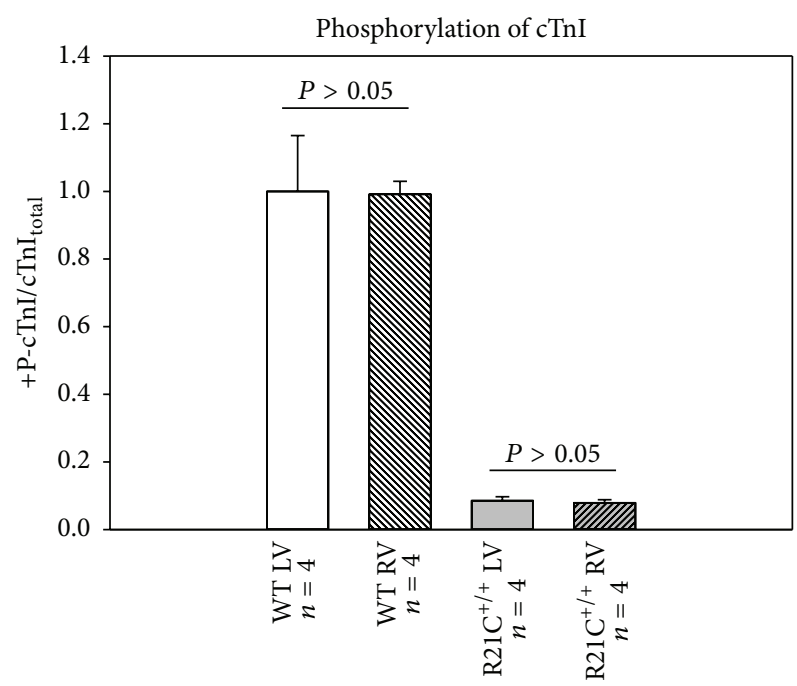

(c)

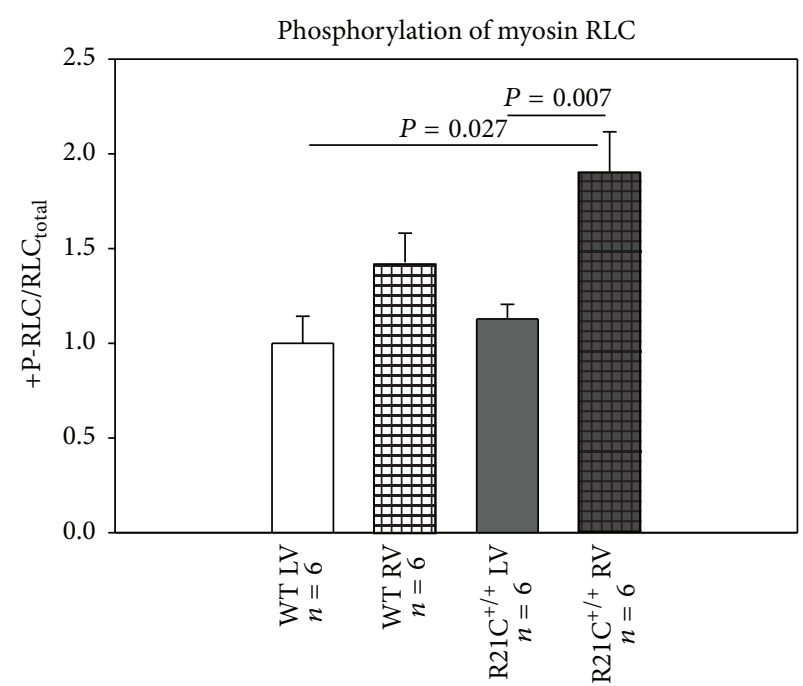

(d)

FIGURE 5: Assessment of protein phosphorylation in LV and RV of R21C ${ }^{+/+}$mice compared with LV and RV of WT mice. (a) Representative ProQ/Coomassie gels of myofibrillar preparations from LV and RV of R21C ${ }^{/+}$mice compared with LV and RV of WT mice. MyBP-C, myosin binding protein C; F/A, F-actin; TnT, troponin T; Tm, tropomyosin; TnI, troponin I, ELC, myosin essential light chain; RLC, myosin regulatory light chain; +P hcTnI std., phosphorylated human cardiac TnI standard; and +P RLC std., phosphorylated human cardiac RLC standard. (b) Representative Western blot of myofibrillar preparations from LV and RV of R21C ${ }^{+/+}$mice compared with LV and RV of WT mice. The level of RLC phosphorylation was determined with phosphospecific RLC antibodies (+P-RLC ab) and compared to the total RLC content assessed with a rabbit polyclonal RLC antibody (CT-1 ab) recognizing total RLC protein. -P RLC std., nonphosphorylated RLC and +P RLC std., phosphorylated RLC standard proteins. (c) Quantification of phosphorylated cTnI was assessed by $n=4$ independent SDS-PAGE (ProQ/Coomassie gels) analyses of two to three preparations from LV and RV ventricles per group. (d) Quantification of RLC phosphorylation was assessed by $n=6$ SDS-PAGE analyses (Western blots and ProQ/Coomassie gels) of two to three LV and RV preparations

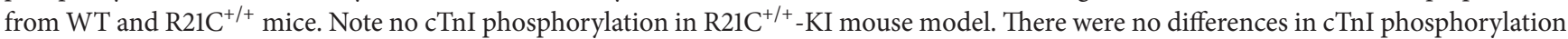
between the LV and RV of WT mice. Note significantly enhanced phosphorylation in the RV-R21C ${ }^{+/+}$compared to LV-R21C $/++(P=0.007)$ and to LV-WT $(P=0.027)$. No statistically significant differences in myosin RLC phosphorylation were observed between the LV and RV of WT mice. Errors bars are SEM. 
(Figures 5(a), 5(b), and 5(d)). Cardiac myosin RLC is a major regulatory subunit of muscle myosin and a modulator of the $\mathrm{Ca}^{2+}$-controlled regulation of muscle contraction [31]. It is localized at the head-rod junction of the myosin heavy chain and it contains the myosin light chain kinase(MLCK-) specific phosphorylatable Ser15. The level of RLC phosphorylation has been shown by us and others to play a critical role in cardiac muscle contraction and in the $\mathrm{Ca}^{2+}$-sensitive interaction of myosin cross-bridges with the actin-containing thin filaments [32-35]. Largely reduced RLC phosphorylation was reported in patients with heart failure $[36,37]$ and observed in animal models of cardiac disease [38-41]. Increased myosin RLC phosphorylation was also observed as a preventive measure of cardiac hypertrophy in mice [42]. Since no significant differences in RLC phosphorylation were noted between the LV and RV of WT mice and $\mathrm{LV}$ of $\mathrm{R}_{2} 1 \mathrm{C}^{+/+}$mice (Figure 5(d)), one can speculate that elevated RLC phosphorylation in the $\mathrm{RV}$ of $\mathrm{R}_{2} 1 \mathrm{C}^{+/+}$mice may play a rescue role alleviating or preventing mutationinduced contractile abnormalities and maintaining the RV tension at the level of WT. Our results indicate that the lower level of RLC phosphorylation in the $\mathrm{LV}$ versus $\mathrm{RV}$ of $\mathrm{R} 21 \mathrm{C}^{+/+}$$\mathrm{KI}$ mice may contribute to the HCM phenotype that can be clearly observed in the $\mathrm{LV}$ and not in the $\mathrm{RV}$ of $\mathrm{R}_{2} 2 \mathrm{C}^{+/+}$mice.

\section{Conflict of Interests}

The authors declare that there is no conflict of interests regarding the publication of this paper.

\section{Acknowledgments}

The authors thank Ms. Michelle Jones for help in editing the paper. This work was supported, in whole or in part, by National Institutes of Health Grants R01 HL042325 and HL108343 (to Danuta Szczesna-Cordary).

\section{References}

[1] J. S. Rankin, P. A. McHale, C. E. Arentzen, D. Ling, J. C. Greenfield Jr., and R. W. Anderson, "The three dimensional dynamic geometry of the left ventricle in the conscious dog," Circulation Research, vol. 39, no. 3, pp. 304-313, 1976.

[2] J. Chen, W. Liu, H. Zhang et al., "Regional ventricular wall thickening reflects changes in cardiac fiber and sheet structure during contraction: quantification with diffusion tensor MRI," The American Journal of Physiology-Heart and Circulatory Physiology, vol. 289, no. 5, pp. H1898-H1907, 2005.

[3] P. M. F. Nielsen, I. J. Le Grice, B. H. Smaill, and P. J. Hunter, "Mathematical model of geometry and fibrous structure of the heart," The American Journal of Physiology-Heart and Circulatory Physiology, vol. 260, part 2, no. 4, pp. H1365-H1378, 1991.

[4] P. P. Sengupta, B. K. Khandheria, J. Korinek, J. Wang, and M. Belohlavek, "Biphasic tissue Doppler waveforms during isovolumic phases are associated with asynchronous deformation of subendocardial and subepicardial layers," Journal of Applied Physiology, vol. 99, no. 3, pp. 1104-1111, 2005.

[5] M. Vendelin, P. H. M. Bovendeerd, J. Engelbrecht, and T. Arts, "Optimizing ventricular fibers: uniform strain or stress, but not
ATP consumption, leads to high efficiency," American Journal of Physiology-Heart and Circulatory Physiology, vol. 283, no. 3, pp. H1072-H1081, 2002.

[6] R. Foale, P. Nihoyannopoulos, W. McKenna et al., "Echocardiographic measurement of the normal adult right ventricle," British Heart Journal, vol. 56, no. 1, pp. 33-44, 1986.

[7] A. M. Gerdes, J. A. Moore, J. M. Hines, P. A. Kirkland, and S. P. Bishop, "Regional differences in myocyte size in normal rat heart," Anatomical Record, vol. 215, no. 4, pp. 420-426, 1986.

[8] J. Wikman-Coffelt, C. Fenner, R. Walsh, A. Salel, T. Kamiyama, and D. T. Mason, "Comparison of mild vs severe pressure overload on the enzymatic activity of myosin in the canine ventricles," Biochemical Medicine, vol. 14, no. 2, pp. 139-146, 1975.

[9] J. Wikman-Coffelt, R. Walsh, C. Fenner, T. Kamiyama, A. Salel, and D. T. Mason, "Activity and molecular changes in right and left ventricular myosins during right ventricular volume overload," Biochemical Medicine, vol. 14, no. 1, pp. 33-41, 1975.

[10] W. S. McMahon, R. Mukherjee, P. C. Gillette, F. A. Crawford, and F. G. Spinale, "Right and left ventricular geometry and myocyte contractile processes with dilated cardiomyopathy: myocyte growth and $\beta$-adrenergic responsiveness," Cardiovascular Research, vol. 31, no. 2, pp. 314-323, 1996.

[11] R. J. Belin, M. P. Sumandea, G. A. Sievert et al., "Interventricular differences in myofilament function in experimental congestive heart failure," Pflügers Archiv European Journal of Physiology, vol. 462, no. 6, pp. 795-809, 2011.

[12] B. Borchert, S. Tripathi, A. Francino, F. Navarro-Lopez, and T. Kraft, "The left and right ventricle of a patient with a R723G mutation of the beta-myosin heavy chain and severe hypertrophic cardiomyopathy show no differences in the expression of myosin mRNA," Cardiology Journal, vol. 17, no. 5, pp. 518-522, 2010.

[13] M. Arad, M. Penas-Lado, L. Monserrat et al., "Gene mutations in apical hypertrophic cardiomyopathy," Circulation, vol. 112, no. 18, pp. 2805-2811, 2005.

[14] Y. Wang, J. R. Pinto, R. S. Solis et al., "Generation and functional characterization of knock-in mice harboring the cardiac troponin I-R21C mutation associated with hypertrophic cardiomyopathy," Journal of Biological Chemistry, vol. 287, no. 3, pp. 2156-2167, 2012.

[15] D. Dweck, M. A. Sanchez-Gonzalez, A. N. Chang et al., "Long term ablation of protein kinase A (PKA)-mediated cardiac troponin I phosphorylation leads to excitation-contraction uncoupling and diastolic dysfunction in a knock-in mouse model of hypertrophic cardiomyopathy," The Journal of Biological Chemistry, vol. 289, no. 33, pp. 23097-23111, 2014.

[16] W. Huang, J. Liang, K. Kazmierczak et al., "Hypertrophic cardiomyopathy associated Lys104Glu mutation in the myosin regulatory light chain causes diastolic disturbance in mice," Journal of Molecular and Cellular Cardiology, vol. 74, pp. 318-329, 2014.

[17] K. Kazmierczak, E. C. Paulino, W. Huang et al., "Discrete effects of A57G-myosin essential light chain mutation associated with familial hypertrophic cardiomyopathy," The American Journal of Physiology-Heart and Circulatory Physiology, vol. 305, no. 4, pp. H575-H589, 2013.

[18] D. Dweck, A. Reyes-Alfonso Jr., and J. D. Potter, "Expanding the range of free calcium regulation in biological solutions," Analytical Biochemistry, vol. 347, no. 2, pp. 303-315, 2005.

[19] D. Szczesna-Cordary, G. Guzman, J. Zhao, O. Hernandez, J. Wei, and Z. Diaz-Perez, "The E22K mutation of myosin RLC that 
causes familial hypertrophic cardiomyopathy increases calcium sensitivity of force and ATPase in transgenic mice," Journal of Cell Science, vol. 118, no. 16, pp. 3675-3683, 2005.

[20] T. L. Hill, E. Eisenberg, and L. Greene, "Theoretical model for the cooperative equilibrium binding of myosin subfragment 1 to the actin-troponin-tropomyosin complex.," Proceedings of the National Academy of Sciences of the United States of America, vol. 77, no. 6, pp. 3186-3190, 1980.

[21] P. Muthu, L. Wang, C.-C. Yuan et al., "Structural and functional aspects of the myosin essential light chain in cardiac muscle contraction," The FASEB Journal, vol. 25, no. 12, pp. 4394-4405, 2011.

[22] L. Wang, P. Muthu, D. Szczesna-Cordary, and M. Kawai, "Characterizations of myosin essential light chain's N-terminal truncation mutant $\Delta 43$ in transgenic mouse papillary muscles by using tension transients in response to sinusoidal length alterations," Journal of Muscle Research and Cell Motility, vol. 34, no. 2, pp. 93-105, 2013.

[23] K. Kazmierczak, P. Muthu, W. Huang, M. Jones, Y. Wang, and D. Szczesna-Cordary, "Myosin regulatory light chain mutation found in hypertrophic cardiomyopathy patients increases isometric force production in transgenic mice," Biochemical Journal, vol. 442, no. 1, pp. 95-103, 2012.

[24] C. L. Perreault, O. H. L. Bing, W. W. Brooks, B. J. Ransil, and J. P. Morgan, "Differential effects of cardiac hypertrophy and failure on right versus left ventricular calcium activation," Circulation Research, vol. 67, no. 3, pp. 707-712, 1990.

[25] R. J. Solaro, A. J. G. Moir, and S. V. Perry, "Phosphorylation of troponin I and the inotropic effect of adrenaline in the perfused rabbit heart," Nature, vol. 262, no. 5569, pp. 615-617, 1976.

[26] P. J. M. Wijnker, A. M. Murphy, G. J. M. Stienen, and J. van der Velden, "Troponin I phosphorylation in human myocardium in health and disease," Netherlands Heart Journal, vol. 22, no. 10, pp. 463-469, 2014.

[27] R. Zhang, J. Zhao, A. Mandveno, and J. D. Potter, "Cardiac troponin I phosphorylation increases the rate of cardiac muscle relaxation," Circulation Research, vol. 76, no. 6, pp. 1028-1035, 1995.

[28] J. C. Kentish, D. T. McCloskey, J. Layland et al., "Phosphorylation of troponin I by protein kinase A accelerates relaxation and crossbridge cycle kinetics in mouse ventricular muscle," Circulation Research, vol. 88, no. 10, pp. 1059-1065, 2001.

[29] A. V. Gomes, K. Harada, and J. D. Potter, "A mutation in the $\mathrm{N}$-terminus of Troponin I that is associated with hypertrophic cardiomyopathy affects the $\mathrm{Ca}^{2+}$-sensitivity, phosphorylation kinetics and proteolytic susceptibility of troponin," Journal of Molecular and Cellular Cardiology, vol. 39, no. 5, pp. 754-765, 2005.

[30] S. B. Marston and P. P. de Tombe, “Troponin phosphorylation and myofilament $\mathrm{Ca}^{2+}$-sensitivity in heart failure: Increased or decreased?" Journal of Molecular and Cellular Cardiology, vol. 45, no. 5, pp. 603-607, 2008.

[31] D. Szczesna, "Regulatory light chains of striated muscle myosin. Structure, function and malfunction," Current Drug TargetsCardiovascular and Haematological Disorders, vol. 3, no. 2, pp. 187-197, 2003.

[32] P. Muthu, K. Kazmierczak, M. Jones, and D. Szczesna-Cordary, "The effect of myosin RLC phosphorylation in normal and cardiomyopathic mouse hearts," Journal of Cellular and Molecular Medicine, vol. 16, no. 4, pp. 911-919, 2012.

[33] P. Muthu, J. Liang, W. Schmidt, J. R. Moore, and D. SzczesnaCordary, "In vitro rescue study of a malignant familial hypertrophic cardiomyopathy phenotype by pseudo-phosphorylation of myosin regulatory light chain," Archives of Biochemistry and Biophysics, vol. 552-553, pp. 29-39, 2014.

[34] S. B. Scruggs and R. J. Solaro, "The significance of regulatory light chain phosphorylation in cardiac physiology," Archives of Biochemistry and Biophysics, vol. 510, no. 2, pp. 129-134, 2011.

[35] C. Toepfer, V. Caorsi, T. Kampourakis et al., "Myosin regulatory light chain (RLC) phosphorylation change as a modulator of cardiac muscle contraction in disease," The Journal of Biological Chemistry, vol. 288, no. 19, pp. 13446-13454, 2013.

[36] J. van der Velden, Z. Papp, N. M. Boontje et al., "The effect of myosin light chain 2 dephosphorylation on $\mathrm{Ca}^{2+}$-sensitivity of force is enhanced in failing human hearts," Cardiovascular Research, vol. 57, no. 2, pp. 505-514, 2003.

[37] J. van der Velden, Z. Papp, R. Zaremba et al., "Increased $\mathrm{Ca}^{2+}$ sensitivity of the contractile apparatus in end-stage human heart failure results from altered phosphorylation of contractile proteins," Cardiovascular Research, vol. 57, no. 1, pp. 37-47, 2003.

[38] T. P. Abraham, M. Jones, K. Kazmierczak et al., "Diastolic dysfunction in familial hypertrophic cardiomyopathy transgenic model mice," Cardiovascular Research, vol. 82, no. 1, pp. 84-92, 2009.

[39] W. Glenn L Kerrick, K. Kazmierczak, Y. Xu, Y. Wang, and D. Szczesna-Cordary, "Malignant familial hypertrophic cardiomyopathy D166V mutation in the ventricular myosin regulatory light chain causes profound effects in skinned and intact papillary muscle fibers from transgenic mice," The FASEB Journal, vol. 23, no. 3, pp. 855-865, 2009.

[40] S. B. Scruggs, A. C. Hinken, A. Thawornkaiwong et al., "Ablation of ventricular myosin regulatory light chain phosphorylation in mice causes cardiac dysfunction in situ and affects neighboring myofilament protein phosphorylation," Journal of Biological Chemistry, vol. 284, no. 8, pp. 5097-5106, 2009.

[41] F. Sheikh, K. Ouyang, S. G. Campbell et al., "Mouse and computational models link Mlc2v dephosphorylation to altered myosin kinetics in early cardiac disease," The Journal of Clinical Investigation, vol. 122, no. 4, pp. 1209-1221, 2012.

[42] J. Huang, J. M. Shelton, J. A. Richardson, K. E. Kamm, and J. T. Stull, "Myosin regulatory light chain phosphorylation attenuates cardiac hypertrophy," Journal of Biological Chemistry, vol. 283, no. 28, pp. 19748-19756, 2008. 

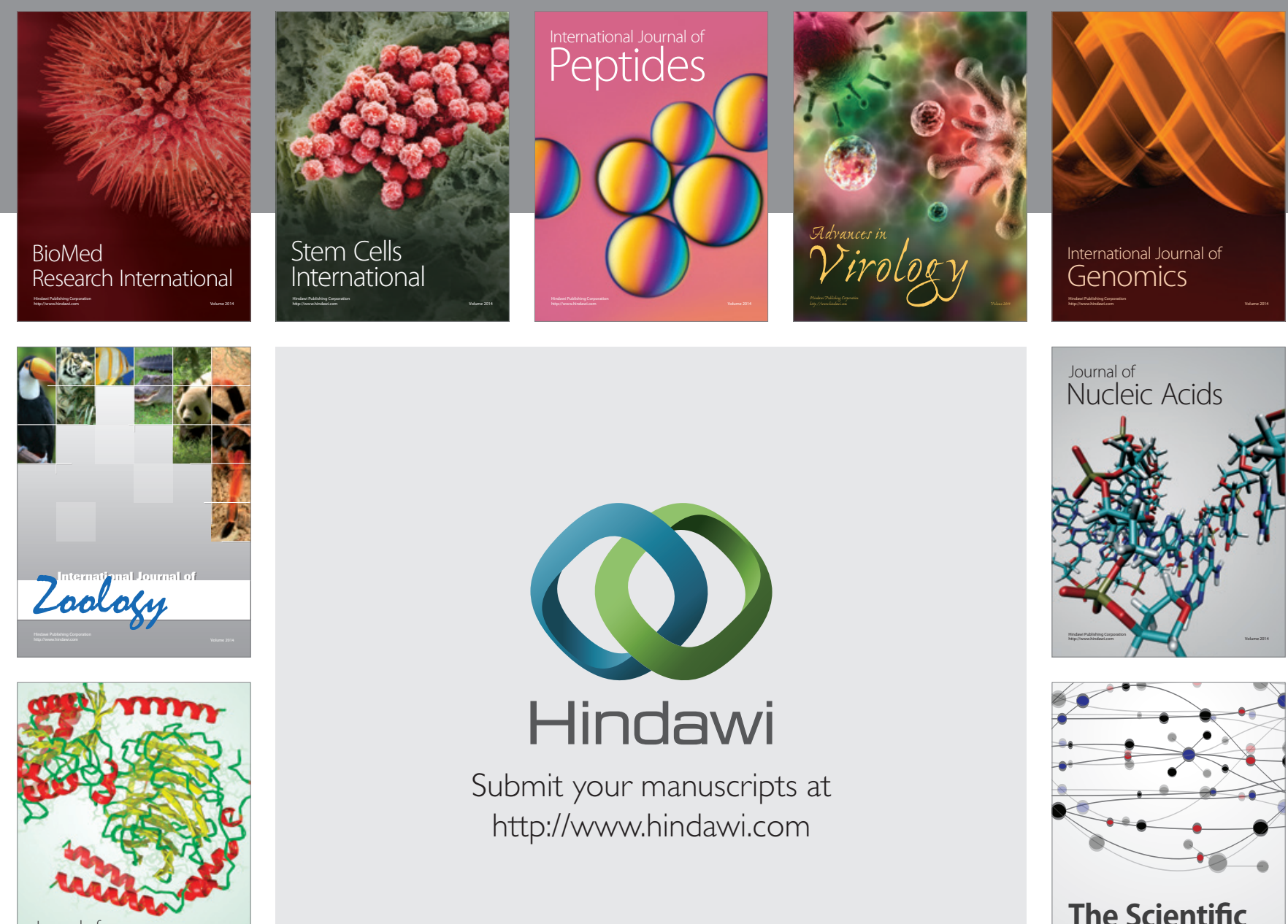

Submit your manuscripts at

http://www.hindawi.com

Journal of
Signal Transduction
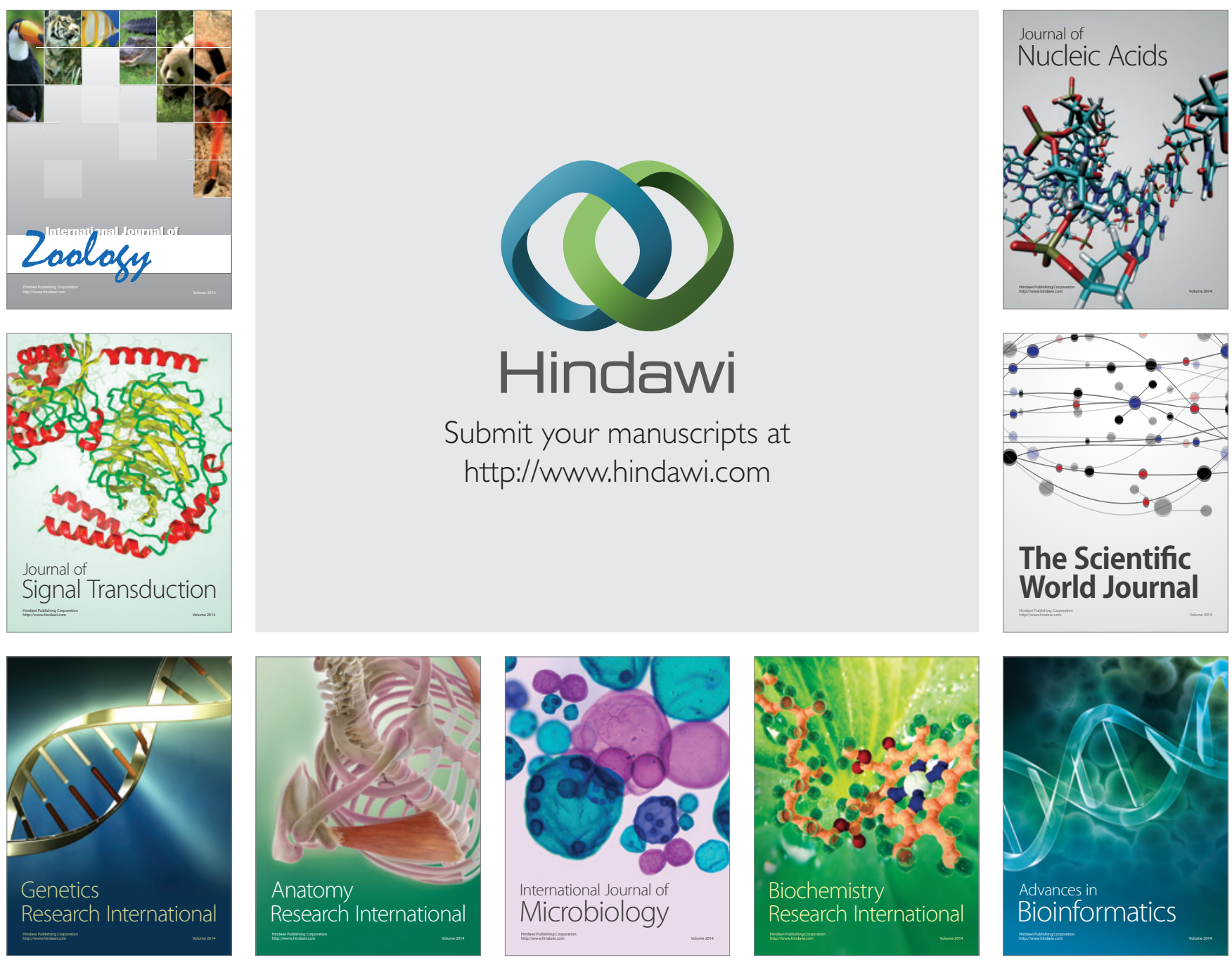

The Scientific World Journal
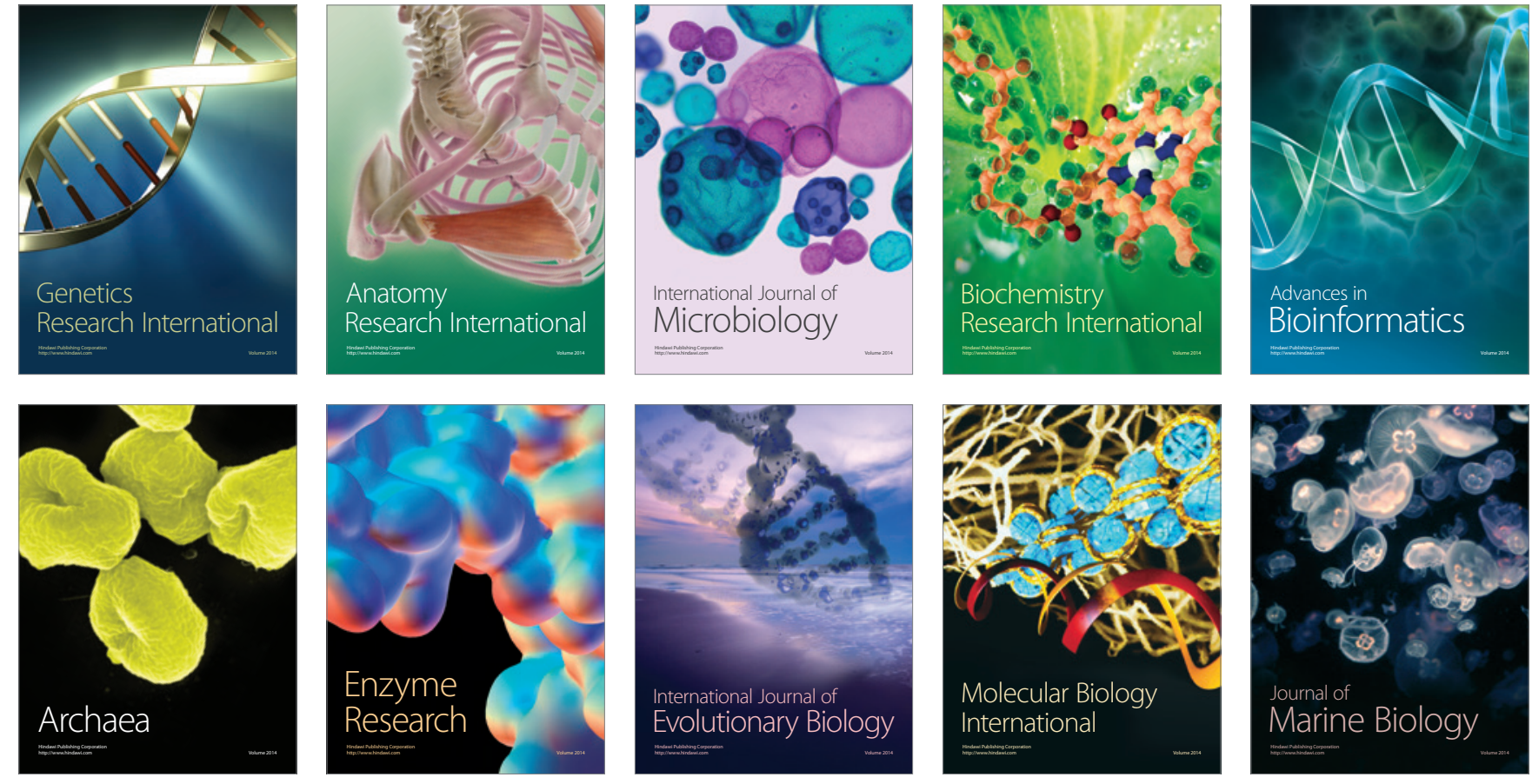